\title{
Juventude e Desamparo: relato de uma pesquisa intervenção
}

\author{
Perla Klautau' \\ Maria Manuela Dias Ramos de Macedo" \\ Marcella Siniscalchi'
}

'Universidade Federal do Rio de Janeiro (UFRJ), Rio de Janeiro/RJ - Brasil "Universidade Federal Fluminense (UFF), Niterói/RJ - Brasil

RESUMO - Juventude e Desamparo: relato de uma pesquisa intervenção. O presente trabalho é fruto de uma intervenção realizada com um grupo de alunos de uma ONG da cidade do Rio de Janeiro, dedicada ao ensino de música clássica para crianças e jovens em situação de vulnerabilidade social. O trabalho de campo se deu em um contexto de educação não-formal, visando conceber a clínica psicanalítica em uma perspectiva ampliada e, ainda, inserir a psicanálise como uma prática capaz de produzir efeitos clínico-políticos. A partir do Diário de Campo produzido ao longo dos encontros, reflexões são tecidas no sentido de analisar quais as repercussões do espaço grupal de acolhimento e de escuta ofertado aos jovens, em um entrelaçamento de teoria e prática.

Palavras-chave: Psicanálise. Clínica Ampliada. Educação Não-Formal. Adolescência. Vulnerabilidade Social.

ABSTRACT - Youth and Helplessness: report of an intervention research. The present work is the result of an intervention carried out with a group of students from an NGO in the city of Rio de Janeiro, dedicated to teaching classical music to children and young people in a situation of social vulnerability. The fieldwork took place in a context of non-formal education, aiming to conceive the psychoanalytic clinic in an expanded perspective and, still, to insert psychoanalysis as a practice capable of producing clinical-political effects. Based on the Field Journal produced during the meetings, reflections are made in order to analyze the repercussions of the group space of reception and listening offered to young people, in an intertwining of theory and practice.

Keywords: Psychoanalysis. Expanded Clinic. Non-Formal Education. Adolescence. Social Vulnerability.

Educação \& Realidade, Porto Alegre, v. 46, n. 1, e109164, 2021 


\section{Desigualdades sociais no campo educacional: vulnerabilidades em questão}

Ao longo deste artigo discutiremos o trabalho de intervenção feito com um grupo de jovens matriculados em uma Organização Não Governamental (ONG) da cidade do Rio de Janeiro, dedicada ao ensino de música clássica para crianças e jovens em situação de vulnerabilidade social. No contexto da pesquisa em questão, o uso do termo juventude faz referência a uma faixa etária expandida entre os 15 e os 25 anos de idade. Trabalhar com jovens em situação de vulnerabilidade social nos leva a considerar, inicialmente, o trabalho psíquico em torno de duas situações de desamparo: uma própria da condição adolescente e outra específica da situação de vulnerabilidade social na qual os jovens em questão se encontram. Trata-se de uma juventude que sofre também de um desamparo do Estado, no sentido de uma falta de garantias para o básico que a coloca à mercê da sociedade, inserida em um contexto cuja marca fundamental é a incerteza.

Trabalhos que atuam na interface adolescência, educação e saúde mental, vêm sendo desenvolvidos por psicanalistas que apostam na possibilidade de realizar uma interlocução entre esses campos de saber (Millot, 2001; Kupfer, 2010; Lajonquière, 2017; Voltolini, 2011; Pereira, 2017; Coutinho; Andrade, 2017; Gurski, Barros; Strzykalski, 2019). Coutinho e Rocha (2007) defendem que a utilização do método psicanalítico em contextos educacionais “[...] pode ser bastante produtiva no atendimento a adolescentes, por tratar-se de uma clínica radicalmente atravessada pelo social, pelo político e pelas instituições, levando em conta as especificidades das operações próprias ao trabalho psíquico da adolescência” (p. 72). Cabe, ainda, ressaltar as múltiplas possibilidades de atuação quando falamos de educação, o que é alertado por Lajonquière durante entrevista concedida a Rodrigues e Reis (2018). É preciso estar atento também aos impasses que envolvem as questões educativas, sem pensar a educação em um sentido único e universal: é preciso levar em consideração as particularidades das regionalidades e dos diferentes sistemas escolares. Na ampliação desse olhar, indicamos o artigo citado acima, de Coutinho e Rocha (2007), quando discorrem sobre uma intervenção psicanalítica realizada em uma escola pública, a chamada educação formal, enquanto Voltolini (2015) e Kupfer (1996) apresentam contribuições obtidas com a utilização da psicanálise na educação inclusiva. Gurski (2017), por sua vez, desenvolve uma pesquisa intervenção em uma instituição de cumprimento de medidas socioeducativas, junto a adolescentes em conflito com a lei. Seguindo tais direções, discutiremos a seguir o relato de uma pesquisa intervenção realizada em um contexto educacional não-formal. Antes de iniciarmos a discussão em questão é preciso entender, de forma breve, como essa modalidade de educação vem ganhando espaço em nosso país.

A Constituição Federal (CF) em vigência no Brasil, datada de 1988, em seu segundo capítulo, intitulado Dos direitos sociais, prevê a garantia do direito à educação a todos cidadãos brasileiros (Brasil, 1988). Ainda que os governos, em suas diferentes esferas, já viessem priorizando a questão escolar mesmo antes de promulgada a CF, a escola até hoje per- 
manece como um produto social desigualmente distribuído. A partir da promulgação do Estatuto da Criança e do Adolescente - ECA (Brasil, 1990), diferentes ações em defesa da proteção integral das crianças e adolescentes e dos seus direitos, como o da educação, passaram a ser priorizadas. Cabe, ainda, ressaltar o papel primordial da escola no que tange o desenvolvimento pessoal e social dos sujeitos. A própria lei no 9.394/96, a qual estabelece as diretrizes e bases da educação nacional, indica que o papel da escola excede a questão da formação acadêmica, contemplando também a formação ética e social do aluno, o desenvolvimento de um pensamento crítico e a temática da cidadania (Brasil, 1996).

Nas últimas décadas, as escolas da rede pública têm se confrontado com a constante falta de sustentação do Estado a partir da retirada de redes de proteção e da adesão ao discurso neoliberal que propaga a ideia de um estado mínimo, enfraquecendo a rede pública. Um Estado que não fornece garantias ao cidadão passa a não ocupar o lugar de confiabilidade: enfraquecido deixa o sujeito à mercê, sem ancoragem, sem garantias, em outras palavras, sem perspectiva de futuro. Este estado de coisas faz com que alunos da rede pública convivam com a incerteza, com a desestabilização e com as condições precárias das instituições de ensino. Apesar disso, continuam enfrentando a cobrança de um bom desempenho e de resultados favoráveis, principalmente no que diz respeito ao rendimento escolar. A conjuntura descrita descortina alguns aspectos do processo de precarização da educação pública que, certamente, contribuiu para o surgimento de ONGs que atuam no contraturno escolar, oferecendo atividades artísticas, esportivas, culturais e, até mesmo, reforço escolar. Esses espaços de educação não formal, também nomeada educação social, têm por objetivo problematizar e interferir no contexto social vigente, carregado de injustiças e desigualdades sociais (Núñez, 2003).

Estados de desigualdade, de injustiça social e de privação material podem produzir um tipo de sofrimento cujas raízes extrapolam o universo da idiossincrasia individual, revelando como a precarização e vulnerabilidade dos laços de pertencimento e coesão social impactam a posição e a experiência do sujeito no mundo - interferindo nos processos de construção identitária (Bourdieu, 1997) e de inscrição do sujeito em estruturas portadoras de sentido (Castel, 1998). É importante reconhecer os efeitos decorrentes da experiência das desigualdades sociais, que desvalorizam, humilham e não reconhecem as potencialidades dos sujeitos, deixando marcas psíquicas com pouca ou nenhuma visibilidade social. Isto é, sofrimentos que têm na sua origem a cruel realidade social (Kleinman; Das; Lock, 1997; Carreteiro, 2003; Furtos, 2007, 2008; Renault, 2008). Para Castel e Haroche (2001), os sujeitos que vivenciam tais sofrimentos acabam não possuindo suportes suficientes para desenvolver estratégias sem ter de recorrer à dependência e, como consequência, acabam passando pelo processo de desfiliação social.

O processo de desfiliação social tem ainda como efeito o desamparo discursivo (Rosa, 2002), o que ocorre quando as estruturas discursivas não são sólidas o suficiente para manter o vínculo social, faltando 
Juventude e Desamparo

aos sujeitos recursos subjetivos que permitam a eles a elaboração de estratégias de defesa para a superação das dificuldades que se apresentam. Para Rosa (2013), essas vivências têm como resultado a perda de laços identificatórios dos semelhantes para com os grupos socialmente excluídos. Esse processo é fruto da condição de invisibilidade e do silenciamento mortífero a que são submetidos, a partir dos discursos hegemônicos da sociedade que lhes retiram a condição de sujeito. Não dispondo da solidariedade, acabam sem ter lugar na sociedade e são lançados para fora da política.

Para o educador e filósofo Paulo Freire (1997), há duas formas de educação: a bancária e a libertadora. A primeira diz respeito a situações em que educandos são vistos apenas como meros objetos, isto é, recipientes a serem preenchidos com conhecimentos. Aos alunos cabe apenas a reprodução da cultura hegemônica e opressora, e não a apreensão da sua realidade ou o desenvolvimento crítico. Como contrapartida, o autor apresenta a proposta de uma educação libertária, capaz de possibilitar a educandos a conscientização da posição de oprimido. Em suas palavras, 0

[...] antagonismo entre as duas concepções, uma, a bancária, que serve à dominação; outra, a problematizadora, que serve à libertação, toma corpo exatamente aí. Enquanto a primeira, necessariamente, mantém a contradição educador-educando, a segunda realiza a superação (p. 71)

Propomos aqui a aproximação do movimento anteriormente descrito com o que o patrono da educação brasileira aponta como efeito da referida educação bancária, já que ao retirar dos educandos a possibilidade de possuírem corpos conscientes também lhes é negada a condição de serem sujeitos. Em outras palavras, essa negação do corpo, legitimada e reproduzida nas instituições escolares, acarreta na incapacidade de compreensão e de comunicação, contribuindo para a reprodução e a manutenção da opressão oriunda das classes dominantes. Nesse sentido, apostamos na construção de espaços coletivos de escuta que potencializem o processo de reconhecimento da anulação da condição de sujeitos ou, dito em outros termos, da negação de seus corpos.

\section{Juventude e Desamparo: um olhar psicanalítico}

Trabalhar com jovens nos leva a considerar de partida o trabalho psíquico em jogo na adolescência, trabalho este que diz respeito à retomada do campo edipiano com a entrada na puberdade e suas implicações no psiquismo (Freud, 1996a). Diferente da puberdade (fenômeno biológico), a adolescência (processos psicológicos) é concebida menos como uma etapa cronológica e mais como uma operação psíquica que não apresenta demarcação nítida no tempo, variando de acordo com cada sujeito e cada cultura. Neste sentido, diversos autores da psicanálise (Rassial, 1997; Lacadée, 2011; Corso; Corso, 2018) utilizam termos como passagem, transição e travessia para falar da operação adolescente, importante em termos de subjetivação e de constituição psíquica, que possibilitaria a assunção da posição de sujeito adulto em nossa socieda- 
de e que vem sendo cada vez mais estendida no tempo, prolongada, ou, até mesmo, nunca sendo realizada por alguns adultos.

Quer dizer, as metamorfoses físicas e biológicas da puberdade, como apontou Freud (1996a), são condições, mas são não suficientes, para que haja uma transformação psíquica e uma mudança na posição subjetiva, necessárias para que o sujeito possa construir uma história pessoal e, ao mesmo tempo, se inserir na coletividade social. O que está em jogo, essencialmente, na transição da adolescência é a possibilidade de o desejo encontrar um destino fora da família através de rearranjos psíquicos e subjetivos. É um período da existência que impõe uma nova construção identitária que permita ao sujeito criar um novo relacionamento consigo mesmo e com o mundo (Pirone; Le Clère, 2014). Desse modo, em termos freudianos, a revivescência do complexo de Édipo na adolescência poderia ser compreendida como uma reedição por sua manifestação ocorrer simultaneamente com a superação das fantasias incestuosas, a separação dos ideais parentais e a escolha de novas referências identificatórias.

Freud (1996a) considerou o desligamento das autoridades e das figuras parentais como "[...] uma das realizações psíquicas mais significativas e também mais dolorosas da época da puberdade" (p. 149). A desidealização dos pais da infância pode deixar o adolescente em contato com um profundo desamparo que o fará recorrer a certas defesas, como a desvalorização dos objetos para negar os sentimentos de dor e perda e a busca de figuras substitutas dos pais no plano social. Estas figuras substitutivas partilhadas socialmente são uma primeira forma de elaborar a perda dos primeiros objetos de amor. Nesse processo de separação dos pais, Kehl (2000) aborda como os grupos de jovens - a função fraterna - podem ajudar a partir das identificações horizontais. Em suas palavras, "[...] é na circulação horizontal que se cria a possibilidade, para os sujeitos, de desenvolvimento de traços identificatórios secundários essenciais para permitir a diversificação de escolhas de destinos" (p. 43). Além disso, servem como suporte para a nova realidade em que o sujeito se encontra e que foi descortinada pelas mudanças do próprio corpo.

Pode-se dizer que há uma situação de vulnerabilidade que é própria da adolescência, pois a travessia do mundo da infância para o mundo adulto implica em perdas, sendo fundamental o trabalho de elaboração de luto não só da condição de criança, mas também dos ideais vinculados às primeiras identificações fundadas no interior da família. A transformação no plano dos objetos amorosos que ocorre na reedição edípica tem como consequência a reelaboração das instâncias dele derivadas - o supereu em sua dimensão de censor e de ideal. Coutinho (2009) pontua que quando as identificações vacilam - seja na adolescência ou em outros momentos da vida - o ideal do eu precisa ser reeditado. Nesse sentido, a reelaboração dos ideais torna-se essencial na transição da adolescência, pois tem a função de permitir uma ideia de si e de orientar o sujeito na existência por servirem como referência para os caminhos do desejo (Coutinho, 2005; Lacadée, 2011). 
Juventude e Desamparo

No entanto, a especificidade desses jovens da camerata diz respeito à incidência em suas subjetividades de dois tipos vulnerabilidade e, portanto, um trabalho psíquico diante de dois desamparos: um próprio da condição adolescente, na qual a dimensão da perda é significativa, e outro próprio da situação de vulnerabilidade social na qual se encontram. Trata-se de uma juventude que sofre também de um desamparo do Estado, no sentido de uma falta de garantias para o básico - como estudo, saúde, moradia e possibilidades de ir e vir - além de ficar à mercê da violência diária presente nas comunidades em que vivem.

A partir do exposto, é possível entender essa juventude está marcada por uma forte incerteza de futuro, no qual o desemprego, por exemplo, parece estar sempre à espreita. Tal perspectiva de um futuro tão incerto, ou até mesmo a privação de um futuro, nos leva a pensar em um incremento do desamparo vivido, que pode até dificultar o trabalho de luto necessário para a saída do registro da perda e construção de um futuro (Siniscalchi, 2019).

\section{Escutando a Camerata}

O primeiro contato feito com a nossa equipe de pesquisa foi efetuado por um dos coordenadores da ONG. Segundo ele, a sinalização da necessidade de psicólogo para acompanhar a camerata partiu do maestro do grupo de jovens músicos que compõem a camerata. O grupo, formado por cerca de quinze jovens com idades entre 15 e 25 anos, é, em sua grande maioria, oriundo do Morro dos Macacos, comunidade localizada na zona norte do Rio de Janeiro, onde funciona um dos núcleos desse projeto de ensino coletivo da música clássica.

Antes de iniciar o trabalho com os jovens, fizemos uma visita ao espaço, quando fomos surpreendidas pela recepção que tivemos: no saguão, um grande grupo nos esperava para uma apresentação especial. Esse foi o nosso primeiro contato com os participantes do projeto social. Após o inesperado acolhimento, o funcionamento da instituição foi esclarecido pelos responsáveis. Com base nos dados apresentados, a intervenção pôde ser estruturada. Cabe ressaltar que a construção da proposta de intervenção com os jovens foi marcada por dois momentos. O primeiro deles, com duração de 3 semanas, consistiu em um período de observações participantes. A partir do conteúdo recolhido, o segundo momento foi então delimitado. Ao longo dos encontros, um diário de campo foi produzido. Essa forma de registro, a partir das nossas observações, constituiu-se como uma importante ferramenta de sistematização das experiências para análise de resultados a posteriori.

Desde o primeiro dia em que fomos apresentadas aos alunos, passamos a estar presentes nos ensaios e nos colocamos disponíveis para atendimentos individuais pontuais em uma sala que nos foi cedida pela coordenação do projeto. Ao longo das semanas iniciais, fomos nos tornando conhecidas pelo grupo e, ainda que diferentes tenham sido os motivos para aproximações, a curiosidade a respeito da nossa presença em um dia específico da semana chamou a atenção das crianças e dos adolescentes. Uma das funcionárias da ONG diz ter sido questionada pelas crianças so- 
bre o fazer do psicólogo. Para explicar construiu uma metáfora que define $o$ psicólogo como uma caixinha de segredos. Já entre os adolescentes, o diálogo partiu de indagações sobre a faculdade, como o caso de um jovem que diz achar psicologia um curso interessante e complementa falando que gostaria de estudar para entender os diferentes comportamentos de quem está no morro e no asfalto.

Ainda durante o momento de observações participantes, conversamos com o maestro que havia solicitado nossa presença para acompanhar o seu grupo, a camerata jovem, e ele nos revelou que, muitas vezes, perdem ótimos alunos pelo fato de que precisam ter vida de adulto quando ainda são crianças ou adolescentes, e que a maioria pensa que se for falar com as psicólogas é porque está ficando maluco. Contou-nos, também, que muitos meninos e meninas do projeto vão conversar e pedir ajuda para ele. Ao final da conversa, o maestro afirma querer participar da nossa intervenção proposta para o grupo de jovens da camerata e reforça que a nossa ajuda é muito importante, ponderando que os alunos sentem vergonha de nos procurar individualmente e revelando, ao mesmo tempo, sua preocupação com quadros de depressão e ansiedade entre os participantes da camerata, bem como sua expectativa em relação a podermos ajudar os alunos a compreender esses quadros.

Considerando o diálogo acima relatado, junto dos dados coletados durante as observações participantes, o segundo momento foi construído. Optou-se por uma modalidade de intervenção coletiva, nomeada Tá na roda. Essa é uma proposta de trabalho com grupos, que vem sendo desenvolvida desde 2015, visando explorar os efeitos da escuta psicanalítica quando aplicada em contextos sociais. Trata-se de um dispositivo estruturado a fim de favorecer a circulação da palavra, promovendo discussões sobre questões levantadas pelos participantes e, principalmente, viabilizando a escuta mútua e o fortalecimento da coletividade (Klautau; Macedo, 2018; Mano et al., 2019).

Para a realização do Tá na roda foram programados cinco encontros. Contudo, por questões institucionais, esse número foi reduzido para quatro. A partir da análise do nosso diário de campo, foi possível identificar algumas especificidades no movimento grupal, o qual dividimos em três tempos: o primeiro, conserto para concerto; o segundo, afinando os instrumentos; e por fim, não existe orquestra de um naipe só.

Para que o funcionamento do Tá na roda operasse entre os jovens, foi importante explicitar o que motivou a criação da atividade, a importância da manutenção do sigilo e o fato de ser um espaço de troca, não havendo, portanto, certo ou errado. Além disso, também foi preciso apresentar alguns pontos que facilitam o funcionamento, tais como: a manutenção do espaço, o sentar em roda e o horário. Esse foi o norte do primeiro encontro, que contou com a apresentação da proposta, dos participantes e das coordenadoras do grupo e com a leitura do Termo de Consentimento Livre e Esclarecido (TCLE). A forma como deveríamos nos apresentar partiu dos próprios jovens, sugerindo que disséssemos nome, idade, se fazemos aquilo que amamos e, no caso deles, o motivo da escolha de instrumento. 
Juventude e Desamparo

Já no primeiro encontro foi possível identificar um forte laço de amizade, especialmente entre os veteranos, os quais já eram amigos mesmo antes do início projeto social e participam desde a sua fundação. Um deles relata que, no momento da matrícula na ONG, a escolha do instrumento foi motivada pela união entre eles: havia quatro vagas para estudar viola eram quatro amigos. Escolhemos para estarmos juntos e nos divertir. Acabamos gostando e estamos juntos até hoje no projeto.

Apesar da sintonia existente no conjunto, evidenciou-se uma desigualdade entre os mais antigos e os que entraram recentemente, em outras palavras, um conflito latente entre os veteranos e os novatos, como se os primeiros compusessem um núcleo central. Além disso, foi possível observar uma discordância por parte dos veteranos em relação à forma de liderança exercida pelo maestro que, de acordo com os mais experientes, deveria ser menos horizontalizada. Para compreender melhor o funcionamento do grupo, é importante saber que a camerata se funda em uma hierarquia, na qual o maestro é a figura principal, atuando como líder do grupo, e, na sequência dele, estão os chefes de naipe de cada instrumento, que são responsáveis pela regência na ausência do primeiro.

$\mathrm{O}$ respeito à hierarquia emerge como uma dificuldade, especialmente no que tange as idades dos participantes. Às vezes eu preciso dar ordens, pois sou chefe do meu naipe, mas, ao mesmo tempo, sou mais novo que o outro que está recebendo as instruções. Nesse ponto, o grupo concorda com a questão levantada, o que não é compartilhado quando outra adversidade surge: falhas na comunicação interna. O próprio desconhecimento por grande parte dos presentes, aponta para a existência de um subgrupo formado pelos mais antigos e, hierarquicamente, mais importantes. Os demais afirmam que muito do que acontece fica nesse grupinho e a gente nem fica sabendo.

Neste momento é importante ressaltar que a demanda pelo trabalho das psicólogas partiu do maestro da camerata que, por sua vez, ocupa uma posição singular no grupo: é, ao mesmo tempo, líder e participante do grupo. Isto é, hierarquicamente, ou pensando verticalmente, ele ocupa uma posição superior, ainda que durante a participação do Tá na roda tenha se posicionado de maneira horizontal, como mais um integrante da pequena orquestra. Tal posição foi um tema recorrente durante a intervenção, o que será retomado mais especificamente na próxima sessão desse artigo.

Durante o primeiro encontro, os jovens se mostraram bastante receptivos e descontraídos na presença das profissionais. Eles faziam perguntas sobre a profissão, curiosos de como é trabalhar ouvindo as pessoas. Rapidamente nos incluíram nas atividades da camerata, solicitando ajuda, pois estavam ficando malucos, em função de um importante concerto agendado para dois meses após o nosso primeiro encontro. Essa apresentação envolvia uma viagem interestadual, a qual foi apresentada como fator de grande pressão. Como solução, dizem vamos comprar mais quatro passagens, vocês ficam lá tomando uma cervejinha para a gente não se matar. Estaria o grupo, então, demandando das psicólogas o seu conserto para o concerto marcado?

A expectativa de que as psicólogas - poderosamente - iriam, enfim, consertar o grupo para o concerto que fariam em poucos meses tratava-se 
de um apelo recorrente feito por eles a diferentes figuras que se alternavam. Em torno do tema da viagem para a apresentação da camerata jovem, apareceram algumas versões de um todo poderoso, como a figura de um herói, que pode salvar (o grupo de psicólogas, por exemplo) e de um todo poderoso que cuida, dá oportunidades, mas também abandona (os padrinhos, patrocinadores e gestores do projeto). Ao longo dos encontros, foi possível perceber, inclusive, que a insatisfação do grupo e suas queixas direcionadas à liderança exercida pelo maestro também diziam respeito a ideia de uma figura poderosa que poderá lhes salvar, o que nos levou a considerar que o desamparo inerente ao adolescer pode ser acrescido, potencializado, pela especificidade da situação de vulnerabilidade social.

A demanda de conserto para concerto revela uma espécie de retorno a um apelo primordial dirigido a uma instância detentora da possibilidade de, nos termos freudianos, realizar uma ação específica que o sujeito, em estado de desamparo, não se encontra em condições de efetuar (Freud, 1999; 1996a). Neste contexto, a palavra alemã Hilflosigkeit, traduzida para o português como desamparo, nomeia um estado de insuficiência e de impotência que caracteriza a condição primordial de o ser humano estar no mundo. Tal situação também pode configurar um estado que pode ser reeditado na adolescência. Quando o infantil adormecido é despertado a partir da imposição do corpo púbere, uma inquietante estranheza é instaurada: o jovem não se reconhece mais a partir do olhar de seus pais, o que traz consigo um estado de desamparo. Com a irrupção da puberdade, o sujeito é tomado de assalto por uma travessia marcada pela urgência de que é preciso mudar e, ao mesmo tempo, continuar o mesmo. Dessa forma, para avançar em direção ao mundo dos adultos, é preciso abrir mão de um pedaço de si ou, em última instância, da condição de dependência infantil. Ao deixar cair uma parte de si a fim de garantir sua sobrevivência frente ao risco de poder se perder por ter tanto o que mudar, o sujeito adolesce. Com isso, um trabalho de luto é engendrado a fim de dar sentido à reelaboração dos ideais na adolescência. O trabalho de luto da perda de um ideal na adolescência pode ser delineado por um movimento em que se alternam desidealização/desilusão e novas idealizações/ilusões que possibilitam o encontro com novos objetos. Trata-se, portanto, de um tempo de tensão entre lutos e a criação de novas ilusões (Siniscalchi, 2019).

No momento em que o sujeito se encontra em plena desidealização das figuras parentais, processo descrito por Freud (1996b; 1996c), e, assim, afasta-se das primeiras influências na constituição dos ideais, ele precisará buscar novas referências identificatórias na cena social. Freud (1996c) demonstrou no texto Algumas reflexões sobre a psicologia do escolar, a partir da relação com os professores na sua própria adolescência, a tendência da criança, desde o período que antecede a puberdade, em recuperar as idealizações da infância que estavam concentradas na figura dos pais, idealizando outros objetos partilhados pela cultura. Ele observou que os jovens parecem buscar no âmbito público pessoas que tenham qualidades que remetam aos seus primeiros objetos idealizados e transferem para os novos objetos sua admiração. 
Juventude e Desamparo

Ou seja, o desligamento do primeiro ideal não é feito de maneira abruta, nem total. Se assim fosse, o sujeito poderia mergulhar em um profundo desamparo, já que os pais idealizados ocupam um lugar fundamental na própria constituição do sujeito. A decepção na relação com o primeiro ideal e as referências identificatórias configura também uma ferida narcísica, de modo que o recurso da idealização parece ser um caminho para que o sujeito possa encontrar novos objetos para investir e recompor seu narcisismo. Ele parece, assim, funcionar como uma primeira forma de lidar com a frustação envolvida nessa perda.

No entanto, a reelaboração dos ideais na adolescência pressupõe que será necessário um desligamento do ideal infantil onipotente que, paradoxalmente, tenta ser resgatado através do investimento nos objetos partilhados socialmente. Quer dizer, num primeiro momento, esses novos objetos encontrados no social são apenas substitutos dos pais idealizados. Será então nessa inserção do sujeito no campo social de forma mais ampla que um trabalho de elaboração poderá provocar uma transformação naquilo que se constituiu originariamente no interior da família.

A partir da queda da idealização dos pais, e, com a decepção frente à promessa edípica, a superação do eu ideal (de caráter onipotente) para o estabelecimento de um ideal do eu se torna possível pela inserção do sujeito nas trocas sociais, que provoca uma modificação na relação com o campo socio-simbólico (Coutinho, 2009). Assim, a passagem da adolescência pressupõe um trabalho de elaboração em torno da falta e da castração. Sobre isto, Alberti (2004) afirma que na adolescência há uma convocação para se iniciar um trabalho de elaboração de escolhas e da falta do Outro - o campo sócio-simbólico. Este tipo de elaboração, quando é atravessada por situações de vulnerabilidade social, pode implicar em um incremento do desamparo vivido pela condição adolescente. Uma das possíveis consequências da realização de um trabalho de subjetivação em condições precárias diz respeito a uma dificuldade de realizar o luto necessário para a saída do registro da perda e construção de um futuro. Nesse sentido, é possível observar uma espécie de paralização diante de situações de perdas, que encontram no registro do apelo uma possibilidade de saída para a falta de perspectiva frente ao que está por vir e, até mesmo, no uso das próprias potencialidades.

\section{Afinando os Instrumentos: da insuficiência do eu ao laço social}

Apesar do clima durante os encontros ser descontraído e permeado por risadas, diversos foram os momentos de angústia. Tais ocasiões revelaram uma sensação de desesperança que foi compartilhada pelo grupo a partir da ideia de dar e tirar, gostar de brincar de Deus. Por detrás das queixas trazidas referentes à presença e à ausência de investimentos financeiros destinados ao projeto social, foi possível compreender a existência de um sentimento compartilhado de abandono e insuficiência. Porém, esses não são os únicos afetos em relação ao poder desempenhado pelo capital econômico. A ambivalência de sentimentos é facilmente identificada, quando os participantes afirmam o papel essencial do financiamento 
para a existência do grupo: sem patrocínio não haveria instrumentos, tampouco o espaço.

Após tal constatação, a confusão no tocante a sentimentos surge perante a outra figura de autoridade, a do maestro. Se, por um lado, é unânime o reconhecimento da sua importância, por outro, muitos o acusam de não saber se posicionar conforme a função que ocupa. $\mathrm{O}$ rapaz foi quem fundou a camerata na unidade do Morro dos Macacos, pouco mais de um ano antes. A ascensão obtida é inquestionável, pois nesse curto espaço de tempo saíram, de acordo com as palavras de um dos integrantes, de apresentações em creches públicas, para crianças melequentas, chegando à melhor sala do Rio de Janeiro. Ainda assim, apontam que as posições de amigo e de maestro se confundem, acarretando na falta de respeito à sua posição de líder.

As acusações trazidas pelos jovens retornam a apontar para um certo desamparo, chegando ao reconhecimento de uma certa orfandade. Eles próprios concordaram se sentirem meio sem pai nem mãe, já que as figuras de poder acabaram por não ocupar as funções, de proteção e amparo.

Teria sido a demanda pelo conserto um apelo às psicanalistas para cumprirem esse papel? Acredita-se que sim! E mais, entende-se que o fato de não acatar ao pedido serviu como combustível para a promoção de um deslocamento: do conserto para a afinação. Isto nos permite entender que a postura assumida pelas psicanalistas permitiu o reconhecimento das potencialidades dentro do próprio grupo, fortalecendo os laços internos.

Dessa maneira, evidencia-se o movimento grupal durante nossa intervenção no sentido de um trabalho de luto da perda de um ideal infantil onipotente. O reconhecimento do desamparo foi um ponto chave para que saídas mais potentes pudessem ser vislumbradas, promovendo um deslocamento das acusações para as características que mantem o grupo unido.

\section{Não Existe Orquestra de um Naipe só: a potência do coletivo diante da angústia}

Judith Butler (2018), na introdução do seu livro Quadros de Guerra: quando a vida é passível de luto?, faz o seguinte questionamento: “[...] o que é uma vida?" (p. 14). Para apresentar a sua discussão, a autora parte da ideia que a vida não está dada de antemão, mas sim que essa é fruto de uma produção. Isto é, para ser, ou para se tornar sujeito, a existência de um corpo vivo não é suficiente, sendo necessária redes de apoio dos seus semelhantes.

Ainda que a precariedade seja uma condição existencial para toda a humanidade, ou seja, todos nós dependemos de redes de sociabilidade, Butler (2018) afirma que, apesar de haver um cruzamento entre precariedade e condição precária, existe uma diferença fundamental entre ambas: o fato de segunda ser socialmente fabricada. 
Juventude e Desamparo

A condição precária designa a condição politicamente induzida na qual certas populações sofrem com redes sociais e econômicas de apoio deficientes [...]. A condição precária também caracteriza a condição politicamente induzida de maximização da precariedade para populações expostas à violência arbitrária do Estado que com frequência não têm opção a não ser recorrer ao próprio Estado contra o qual precisam de proteção (p. 46).

O cenário apresentado nos leva a refletir sobre quais, então, seriam as possíveis alternativas para os grupos em tais condições precárias. Se para Butler (2018) as saídas estão em torno de coligações, entendemos que a aposta da psicanálise no âmbito coletivo seja uma potente alternativa pautada na potencialização de um discurso que sustente novas possibilidades de laços sociais para esses sujeitos.

Durante a atividade proposta, foi muito interessante ver, especialmente nos dois últimos encontros, os jovens se reconhecendo enquanto grupo, cada um com sua singularidade, mas que para a camerata funcionar, todos ali eram necessários. A partir de uma conversa a respeito da formação do grupo ter se dado através da parceria, chegouse, portanto, à diferenciação entre parceria e dependência. Esse diálogo permitiu a eles falarem sobre as relações que se dão de forma vertical, ou seja, de poder, quando um depende do outro, e de maneira horizontal, quando há união e todas as partes crescem juntas. Em posse desses conceitos, pensando o funcionamento da camerata, entendem que um naipe depende do outro, mas que a relação entre eles, musicistas, é de parceria. Portanto, cada componente tem a sua importância e todos são fundamentais para que o concerto aconteça.

Se, em um momento a circulação da palavra tomou um tom acusatório, especialmente por parte daqueles mais engajados no projeto, os quais reclamavam de ausências ou falta de empenho de alguns, mais para o fim da atividade, as queixas deixaram de ser motor para o funcionamento do grupo, convertendo-se em escuta de vivências pessoais. Uma participante fala que tem outras atividades além do projeto, ainda estuda e trabalha, pois precisa ajudar no sustento da casa. Outra conta que precisa cuidar da sua avó, enquanto um terceiro participante está passando por uma situação de despejo, precisando encontrar uma moradia. As singularidades que compõem o grupo emergem e, entre eles, passam a buscar estratégias para tecer redes que os possibilitem amparar uns aos outros.

Já próximo de encerrarmos o último encontro, o maestro pede a palavra e, agradecendo a nossa participação, expõe que solicitou a nossa presença justamente por achar importante a oportunidade de todos se escutarem. Conta que fica na posição de tentar manejar as situações que se apresentam, compreendendo as adversidades vividas por cada um. Ainda que por vezes seja visto como um líder pouco enérgico, ressalta que, antes de tudo, eles são amigos. Em suas palavras, a amizade é o diferencial desse grupo. As pessoas, quando nos escutam, sentem uma energia diferente. E, se isso se perder, nós viramos um grupo qualquer. 
Foi interessante ver a relevância da amizade apontada pela figura principal desse grupo de jovens, já que na adolescência, esse laço da vida social tem um papel bastante específico. A amizade, nessa etapa de elaboração da vida psíquica, serve de propulsor do afrouxamento das relações primárias, inaugurando uma possível construção de autonomia do pensamento e da fala (Brun, 2007). Nesse sentido, Barretto (2019) nos propõe refletir sobre a subversividade existente na força da amizade, considerando o seu potencial de "[...] transformação social e individual, capaz de produzir outras formas de sociabilidade, em que a pluralidade, o dissenso e o próprio conflito sejam propulsores da vida coletiva" (p. 14).

Ao final do trabalho, foi possível aos participantes reconhecer que há algo muito forte e especial que os une: a amizade. Ainda assim, as singularidades não deixam de existir. Pelo contrário, é a união das coletividades, aliada ao fortalecimento de uma rede de apoio mútuo, que permite a sua existência, o que olhando a posteriori pode até parecer óbvio, afinal: não existe orquestra de um naipe só!

\section{Considerações Finais}

Tendo em vista a realidade e os desafios da educação brasileira, a escolha pela construção de um dispositivo escuta analítica no coletivo se fundamentou no fato desses operarem no sentido de potencializar os vínculos entre os sujeitos, tão afrouxados pela lógica individualizante e excludente da sociedade contemporânea. Especialmente em contextos marcados pela vulnerabilidade social, a criação de espaços que tem como ferramenta principal a escuta do inconsciente faz parte da estratégia de ação quando se desenvolvem atividades grupais. Os impactos positivos decorrentes de tais ações, frutos do alargamento da aplicabilidade da psicanálise, visando, especialmente, à sua utilização nos espaços sociais, são destacados por diversos psicanalistas, com ênfase na extrapolação do âmbito clínico, chegando a produzir efeitos também políticos (Rosa, 2013; Broide; Broide, 2016; Barreto, 2019).

Retomando as ideias de Paulo Freire, apresentadas previamente, podemos as aproximar do observado ao longo da intervenção. A verticalidade demandada pelos participantes vai de encontro à lógica da educação bancária, opressora e autoritária. Nessa concepção de educação, não há espaço para o diálogo, sendo um exercício de adaptação do sujeito ao mundo. É importante termos em mente que esse é o modelo conhecido por esses jovens e, assim, por eles assimilado como correto ou como supostamente deveria ser. Em contrapartida, a superação da díade educador-educando permite a relação horizontal, que não somente humaniza, mas ainda contra-aliena os sujeitos, promovendo reflexões sobre a realidade e sobre o mundo.

Apesar do estranhamento e do mal estar causado nos jovens quando não havia figuras ocupando a posição de dominação, fossem as psicanalistas ou o maestro, abriu-se espaço para emergir o reconhecimento de si como corpos conscientes e potentes. Assim como na educação libertadora, em que há a constante circulação da palavra entre

Educação \& Realidade, Porto Alegre, v. 46, n. 1, e109164, 2021. 
Juventude e Desamparo

educandos e educadores, na proposta de articular educação, psicanálise e adolescência, temos a escuta como ferramenta que fundamenta a possibilidade de transformação social.

Recebido em 12 de novembro de 2020 Aprovado em 30 de março de 2021

\section{Referências}

ALBERTI, Sonia. O Adolescente e o Outro. Rio de Janeiro: Zahar, 2004.

BARRETTO, Flavia Cavalcanti. Tecendo 'Nós': um estudo psicanalítico sobre a amizade entre jovens em contexto de violências extremas. 2019. 142 f. Dissertação (Mestrado em Psicologia Clínica) - Programa de Pós-Graduação em Psicologia Clínica, Universidade Católica de Pernambuco, Recife, 2019.

BOURDIEU, Pierre. A Miséria do Mundo. Petrópolis: Vozes, 4ª ed., 1997.

BRASIL. Constituição da República Federativa do Brasil. Diário Oficial da União, Brasília, 1988.

BRASIL. Estatuto da Criança e do Adolescente. Brasília: Editora da Fenabb, 1990.

BRASIL. Ministério da Educação. Lei de Diretrizes e Bases da Educação Nacional. Diário Oficial da União, Brasília, 1996.

BROIDE, Jorge; BROIDE, Emilia Estivalet. A Psicanálise em Situações Sociais Críticas: metodologia clínica e intervenções. São Paulo: Editora Escuta, 2016.

BRUN, Danièle. A Gramática Amorosa da Amizade. Ágora: estudos em teoria psicanalítica, v. 10, n. 2, p. 311-319, 2007.

BUTLER, Judith. Quadros de Guerra: quando a vida é passível de luto? Rio de Janeiro: Civilização Brasileira, 2018.

CARRETEIRO, Teresa Cristina. Sofrimentos Sociais em Debate. Psicologia USP São Paulo, v. 14, n. 3, p. 57-72, 2003.

CASTEL, Robert. Metamorfoses da Questão Social. Uma crônica do salário. Petrópolis: Vozes, 1998.

CASTEL, Robert; HAROCHE, Claudine. Propriété Privée, Propriété Sociale, Propriété de Soi. Paris: Fayard, 2001.

CORSO, Diana; CORSO, Mario. Adolescência em Cartaz: filmes e psicanálise para entendê-la. Porto Alegre: Artmed, 2018.

COUTINHO, Luciana Gageiro. A Adolescência na Contemporaneidade: ideal cultural ou sintoma social? Pulsional Revista de Psicanálise, v. 181, n. 3, p. 1624, 2005.

COUTINHO, Luciana Gageiro. Adolescência e Errância: destinos do laço social no contemporâneo. Rio de Janeiro: Nau, FAPERJ, 2009.

COUTINHO, Luciana Gageiro; ANDRADE, Claudia Braga de. O Que as Ocupações nos Ensinam Sobre a Adolescência, o Laço Social e a Educação? ETD-Educação Temática Digital, v. 19, p. 48-62, 2017.

COUTINHO, Luciana Gageiro; ROCHA, Ana Paula Rongel. Grupos de Reflexão com Adolescentes: elementos para uma escuta psicanalítica na escola. Psicologia Clínica, v. 19, n. 2, p. 71-85, 2007.

FREIRE, Paulo. Educação ‘Bancária’ e Educação Libertadora. In: PATTO, Maria Helena Souza. Introdução à Psicologia Escolar. São Paulo: Casa do Psicólog, 1997. P. 61-78. FREUD, Sigmund. Três ensaios para uma teoria da sexualidade. In: FREUD, Sigmund. Edição Standard Brasileira das Obras Completas de Sigmund Freud (Vol. VII). Rio de Janeiro: Imago, 1996a. P. 119 -235. [1905] 
FREUD, Sigmund. Romances Familiares. In: FREUD, Sigmund. Edição Standard Brasileira das Obras Completas de Sigmund Freud (Vol. IX). Rio de Janeiro: Imago, 1996b. P. 217-222. [1909/1908]

FREUD, Sigmund. Algumas Reflexões sobre a Psicologia do Escolar. In: FREUD, Sigmund. Edição Standard Brasileira das Obras Completas de Sigmund Freud (Vol. XIII). Rio de Janeiro: Imago, 1996c. P. 251-258. [1914].

FREUD, Sigmund. Projeto para uma Psicologia Científica. In: FREUD, Sigmund. Edição Standard Brasileira das Obras Completas de Sigmund Freud (Vol. I). Rio de Janeiro: Imago, 1999. P. 341-481. [1950/1895].

FURTOS, Jean. Les Effets Cliniques de la Souffrance Psychique d'Origine Sociale. Mental Idées, n.11, 2007.

FURTOS, Jean. Le Syndrome d'Auto-Exclusion. In: FURTOS, Jean. Les Cliniques de la Précarité: contexte social, psychopathologie et dispositifs. Paris: Elsevier Masson, 2008.

GURSKI, Rose. Jovens 'Infratores', o RAP e o Poetar: deslizamentos da 'vida nua' à 'vida loka'. Subjetividade, v. 17, n. 3, p. 45-56, 2017.

GURSKI, Rose; BARROS, Jane Fischer; STRZYKALSKI, Stéphanie. O Enlace entre Psicanálise, Educação, Cinema e a Experiência Adolescente. Educação \& Realidade, Porto Alegre, v. 44, n. 2, p. 1-17, 2019.

KEHL, Maria Rita. Existe uma Função Fraterna? In: KEHL, Maria Rita (Org.). Função Fraterna. Rio de Janeiro: Relume Dumará, 2000. P. 31-47.

KLAUTAU, Perla; MACEDO, Maria Manuela Dias Ramos de. Construção de Dispositivos de Escuta Para Jovens em Busca de um Futuro Profissional: impasses e apostas da psicanálise em extensão. Tempo Psicanalítico, v. 50, n. 2, p. 245-264, 2018.

KLEINMAN, Arthur; DAS, Veena; LOCK, Margaret (Org.). Social Suffering. Berkeley: University of California Press, 1997.

KUPFER, Maria Cristina Machado. Pré-Escola Terapêutica Lugar de Vida: um dispositivo para o tratamento de crianças com distúrbios globais do desenvolvimento. Estilos da Clínica, v. 1, n. 1, p. 8-17, 1996.

KUPFER, Maria Cristina Machado. O Sujeito na Psicanálise e na Educação: bases para a educação terapêutica. Educação \& Realidade, Porto Alegre, v. 35, n. 1, p. 265 282, 2010.

LACADÉE, Philippe. O Despertar e o Exílio: ensinamentos psicanalíticos da mais delicada das transições, a adolescência. Rio de Janeiro: Contra Capa Livraria, Opção Lacaniana, 2011.

LAJONQUIÈRE, Leandro de. Elucidação Comparativa dos Estudos em Psicanálise e Educação na França e no Brasil: a psicanálise aplica-se à educação? Educar em revista, n. 64, p. 19-33, 2017.

MANO, Beatriz Chacur et al. Roda de Conversa: espaço para jovens em situação de vilnerabilidade social. In: DADOORIAN, Diana; FAGUNDES, Laura Maria Reis; PEREIRA, Claudia Rodrigues (Org.). Círculo Psicanalítico do Rio de Janeiro: 50 anos. Rio de Janeiro: Círculo Psicanalítico, 2019. P. 145-150.

MILLOT, Catherine. Freud Antipedagogo: Rio de Janeiro: Zahar, 2001.

NÚÑEZ, Violeta. El Lugar de la Educación Frente a la Asignación Social de los Destinos. In: MOLINA, José García. De Novo, la Educación Social. Madrid: Dykinson, 2003. P. 209-218. 
PEREIRA, Marcelo Ricardo. De Que Hoje Padecem os Professores da Educação Básica? Educar em Revista, n. 64, p. 71-87, 2017.

PIRONE, Ilaria; LE CLÈRE, François. La Relation Éducative Affectée: éclairages cliniques et philosophiques sur les pannes de la relation éducative entre adultes et adolescentes. Educatio, n. 3, 2014.

RASSIAL, Jean Jacques. A Passagem Adolescente - da família ao laço social. Porto Alegre: Artes e Ofícios, 1997.

RENAULT, Emmanuel. Souffrances Socialles: sociologie, psychologie et politique. Paris: Le Découverte, 2008.

RODRIGUES, Rogério; REIS, Magali. A Ilusão (Psico)Pedagógica e o Empobrecimento das Experiências Educativas (Entrevista a Leandro de Lajonquière). Estilos da Clínica, v. 23, n. 2, p. 430-450, 2018.

ROSA, Miriam Debieux. Uma Escuta Psicanalítica das Vidas Secas. Revista Textura, São Paulo, ano 2, n. 2, p. 42-47, 2002.

ROSA, Miriam Debieux. Psicanálise Implicada Vicissitudes das Práticas Clinicopolíticas. Revista da Associação Psicanalítica de Porto Alegre, Porto Alegre, v. 41, p. 29-40, 2013

SINISCALCHI, Marcella Bueno Brandão. Adolescência e Luto: a escrita de Fanfictions na contemporaneidade. 2019. 113 f. Dissertação (Mestrado em Psicologia) - Programa de Pós-Graduação em Psicologia, Universidade Federal do Rio de Janeiro, Rio de Janeiro, 2019.

VOLTOLINI, Rinaldo. Educação e Psicanálise. Rio de Janeiro: Zahar, 2011.

VOLTOLINI, Rinaldo. Miséria Ética na Educação Inclusiva: por uma inclusão política mais do que social. Educação, v. 38, n. 2, p. 222-229, 2015.

Perla Klautau é Professora do Instituto de Psicologia da UFRJ, Psicanalista, Membro efetivo do Círculo Psicanalítico do Rio de Janeiro.

ORCID: http://orcid.org/0000-0003-4578-0795

E-mail:pklautau@uol.com.br

Maria Manuela Dias Ramos de Macedo é Psicóloga Clínica formada pela Universidade Veiga de Almeida, mestranda em Educação pela Universidade Federal Fluminense e Membro Associado em Formação do Círculo Psicanalítico do Rio de Janeiro.

ORCID: http://orcid.org/0000-0003-0476-5951

E-mail: mariamanuelarm@gmail.com

Marcella Siniscalchi é Psicóloga Clínica com orientação psicanalítica. Graduada em Psicologia pela Pontifícia Universidade Católica do Rio de Janeiro. Mestre em Psicologia pelo Instituto de Psicologia da Universidade Federal do Rio de Janeiro.

ORCID: http://orcid.org/0000-0002-4291-149X

E-mail: marcella.bbs@gmail.com

Editora-Responsável: Fabiana de Amorim Marcello

Este é um artigo de acesso aberto distribuído sob os termos de uma Licença Creative Commons Atribuição 4.0 Internacional. Disponível em: <http:// creativecommons.org/licenses/by/4.0>. 